\title{
Chinese and Japanese outshine US schoolchildren in maths
}

\section{Washington}

THI abysmal mathematical skills of US schoolchildren as compared with their Chinese and Japanese counterparts have prompted a new wave of concern about teaching methods and curricula in US schools. The newly formed Mathematical Sciences Education Board (MSEB) is so concerned it is developing the first national guidelines for mathematics curricula, a radical act in a country where the independence of local school boards is a cherished political freedom.

That typical US schoolchildren are casily outperformed by Chinese and Japanese children at all ages from kindergarten up has been known for some time. Possible reasons - and solutions - were discussed two weeks ago at a meeting held by the board in Washington. DC.

The figures are disturbing: according to a new analysis of the Second International Mathematics Study presented at the meeting, US students at the ages of 13 and 17

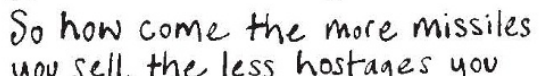
you sell, the less hostages you

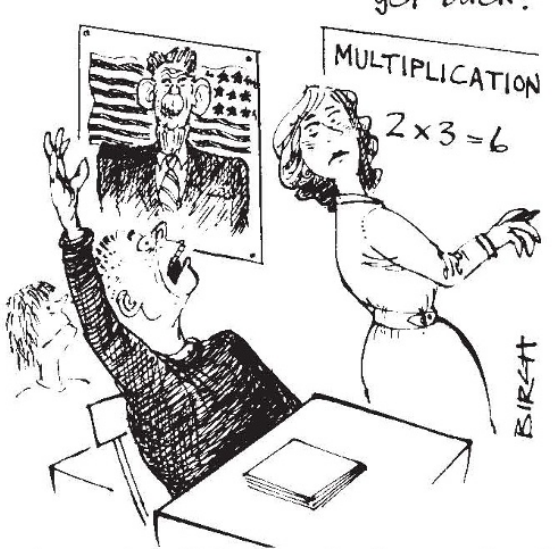

performed well below the international average of 17 countries in the study at problem-solving tasks (as distinct from computational tasks). In some, the US students were ranked in the lowest quarter of the countries sampled and the lowest of the advanced industrialized countries.

The reasons may not be hard to find According to a study presented by James Stigler of the University of Chicago which compared US, Chinese and Japanese pupils, US children at the ages of 6 and 10 spend substantially less time engaged in "academic activities" than their Asian equivalents. By the age of 10 , US children are spending fewer than 20 hours per week at work, as compared with 40 hours in China and 32 in Japan. Furthermore, the percentage of study time devoted to mathematics was lower in the United States than in the other two countries, and the children spent more time engaged in "in- appropriate activities". Stigler comments that Chinese and Japanese teachers appear better prepared for teaching mathematics than US teachers.

Whatever the reasons, the United States poor showing is deemed a matter

of serious concern by officials in the White House's (Office of Science and Technology Policy. Education Secretary William Bennett has shown an awareness of the problem by publishing his own study of Japanese education, although he supports the Reagan administration line that there should be no national curriculum like that in Japan. If MSEI3 has its way, there will at least be a standard against which curricula can be measured

Tim Beardsley

\section{Multi-million dollar vaccination drive against infant mortality}

\section{New Delhi}

In the next five years, at a cost of US\$2.50 million, 82 million infants and 92 million expectant mothers will be immunized in India against six childhood diseases polio, tetanus, diphtheria, measles, tuberculosis and whooping cough - in an ambitious programme aimed at reducing infant mortality by half hefore the end of the decade. At present. one in every nine babies dies before its first birthday

The Universal Immunisation Programme (UIP) will involve administering 820 million doses of vaccine. It will be implemented as part of a primary health care programme through a network of $30.0(0)$ grassroot workers, each of whom will be given a motorized cycle and a vaccine carrier (ice box). The vaccine carrier is the last and the cheapest item in the $\$ 60$ million's worth of cooling equipment that includes refrigerated trucks, 275 walk-in coolers, 2,125 deep freezes, $28,0(0)$ icelined refrigerators and 800 vans for transporting vaccines.

The programme is backed by the World Health Organisation (WHO), UNICEF and other international agencies. But in spite of its laudable cbjective, UIP is seen by critics as one more programme imposed by outside agencies without regard to the primary health-care philosophy of self-help.

"By inhibiting community self-reliance and social control over medical technology . . . our people are once again being made dependent on Western countries for funds, vaccines and equipment", says Dr D. Banerjee, professor of social medicine at the Jawaharlal Nehru University in New Delhi.

India does not manufacture measles vaccine, which has to be imported together with much of the cold equipment, such as refrigerators running on sunlight or kerosene. To meet the target, India has to double its production of other vaccines or rely on imports. Plans are already under way to import technologies for making safer vaccines. According to WHO's own estimates, its immunization programme in the developing countries is turning into $\$ 25$-million-a-year business for industrialized countries which now supply 85 per eent of the equipment and products for cold storage

Concern has also been expressed about the wisdom of a massive vaccination programme in the absence of a mechanism for strict quality control of the vaccines. Ten children died recently in a Bombay hospital after receiving DP'T (diptheria) pertussis tetanus) vaccine made by one of India's premier laboratories. There have been several cases of polio among vaccinated children.

Banerjee says that "saturation spraying with vaccines" has been launched without basic epidemiological data. "The imposition of a selective approach, in the short term, in the name of saving children, is diverting scarce resources from the underlying need for comprehensive primary health care." K.S. Jayaraman

\section{When the wind blows}

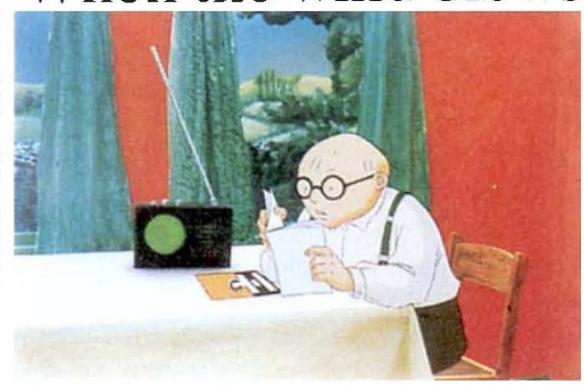

Jim Bloggs reads up on how to survive the holocaust.

THF effects of a nuclear attack have been animated in the form of a cartoon version of Raymond Briggs's successful book and radio/stage play When The Wind Blows. The film features the voices of Sir John Mills and Dame Peggy Ashcroft as Jim and Hilda Bloggs, the heroes of the film, who outline their fears and hopes as they find themselves survivors of a nuclear attack. When The Wind Blows can be seen around Britain from 6 February.

Almost naively, Jim and Hilda, a typical English retired couple, attempt to face the aftermath of a nuclear attack "with the same faith and optimism with which they once faced the Blitz". 